\title{
Anti-angiogenic action of hyperthermia by suppressing gene expression and production of tumour-derived vascular endothelial growth factor in vivo and in vitro
}

\author{
Y Sawaji', T Sato*,', A Takeuchi' ${ }^{2}$ M Hirata' and A Ito' \\ 'Department of Biochemistry, School of Pharmacy, Tokyo University of Pharmacy and Life Science, 1432-I Horinouchi, Hachioji, Tokyo 192-0392, Japan; \\ ${ }^{2}$ Department of Thermotherapy, Luke Hospital, Nakano, Tokyo 165-0027, Japan
}

Vascular endothelial growth factor is an important angiogenic factor for tumour progression because it increases endothelialcell proliferation and remodels extracellular matrix in blood vessels. We demonstrated that hyperthermia at $42^{\circ} \mathrm{C}$, termed heat shock, suppressed the gene expression and production of vascular endothelial growth factor in human fibrosarcoma HT1080 cells and inhibited its in vitro angiogenic action on human umbilical vein endothelial cells. The gene expression of alternative splicing variants for vascular endothelial growth factor, VEGF $121, V E G F_{165}$ and $V E G F_{189}$, was constitutively detected in HT-I080 cells, but the VEGF 189 transcript was less abundant than VEGF 121 and VEGF 165 . When HT-I080 cells were treated with heat shock at $42^{\circ} \mathrm{C}$ for $4 \mathrm{~h}$ and then maintained at $37^{\circ} \mathrm{C}$ for another $24 \mathrm{~h}$, the gene expression of all vascular endothelial growth factor variants was suppressed. In addition, HT- 1080 cells were found to produce abundant VEGF 165 , but much less VEGF 121 , both of which were inhibited by heat shock. Furthermore, the level of vascular endothelial growth factor in sera from six cancer patients was significantly diminished $2-3$ weeks after completion of whole-body hyperthermia at $42^{\circ} \mathrm{C}$ $\left(49.9 \pm 36.5 \mathrm{pg} \mathrm{ml}^{-1}, P<0.0 \mathrm{I}\right)$ as compared with that prior to the treatment $\left(177.0 \pm 77.5 \mathrm{pg} \mathrm{ml}^{-1}\right)$. On the other hand, HT-I080 cell-conditioned medium showed vascular endothelial growth factor-dependent cell proliferative activity and the augmentation of pro-matrix metalloproteinase-I production in human umbilical vein endothelial cells. The augmentation of endothelial-cell proliferation and pro-matrix metalloproteinase-I production was poor when human umbilical vein endothelial cells were treated with conditioned medium from heat-shocked HT-I 080 cells. These results suggest that hyperthermia acts as an anti-angiogenic strategy by suppressing the expression of tumour-derived vascular endothelial growth factor production and thereby inhibiting endothelial-cell proliferation and extracellular matrix remodelling in blood vessels. British Journal of Cancer (2002) 86, I597- 1603. DOl: 10.1038/sj/bjc/6600268 www.bjcancer.com

(c) 2002 Cancer Research UK

Keywords: VEGF; hyperthermia; angiogenesis; endothelial-cell; tumour metastasis

Angiogenesis is essential for tumour development and metastasis, and tumour-derived angiogenic factor(s) play(s) an important role in the formation of new vessels and tumour progression in vivo and in vitro (Weidner et al, 1991; Ferrara et al, 1992; Folkman, 1992). Vascular endothelial growth factor (VEGF) (Ferrara and Henzel, 1989; Leung et al, 1989), basic fibroblast growth factor (bFGF) (Abraham et al, 1986; Gospodarowicz et al, 1987), transforming growth factor- $\alpha$ (TGF- $\alpha$ ) (Schreiber et al, 1986) and platelet-derived growth factor (Holmgren et al, 1991; Risau et al, 1992) all have been identified as angiogenic factors. Among them, VEGF is considered to be the pivotal factor in tumour neovascularisation, because it increases in endothelial-cell proliferation and migration (Leung et al, 1989; Connolly et al, 1989; Ferrara et al, 1992), enhancement of tumour growth in vivo (Kondo et al, 1993, 2000) and remodelling of perivascular matrices by augmenting proteinases such as matrix metalloproteinases (MMPs) (Fisher et al, 1994; Moses, 1997).

VEGF is a $34-42 \mathrm{kDa}$ heparin-binding and dimeric glycoprotein, and four isoforms have been characterised. Three of these,

\footnotetext{
*Correspondence: T Sato; E-mail: satotak@ps.toyaku.ac.jp
}

Received 30 July 200 I; revised 19 February 2002; accepted I March 2002
$\mathrm{VEGF}_{121}, \mathrm{VEGF}_{165}$ and $\mathrm{VEGF}_{189}$ are composed of 121, 165 and 189 amino acids, respectively, and are generated by alternative splicing of eight exons (Tischer et al, 1991). $\mathrm{VEGF}_{189}$ is encoded by all the exons, and $\mathrm{VEGF}_{165}$ and $\mathrm{VEGF}_{121}$ are missing the amino acid residues corresponding to exon 6 and exons 6 and 7, respectively (Tischer et al, 1991). The fourth VEGF cDNA species, VEGF 206 was discovered in a human foetal-liver cDNA library and the gene codes for a predicted protein with 206 amino acids. In comparison to $\mathrm{VEGF}_{165}, \mathrm{VEGF}_{206}$ contains an additional 41 amino acids between exons 5 and 7 as well as a basic 24 amino acid insertion also found in $\mathrm{VEGF}_{189}$ (Houck et al, 1991). VEGF 165 and VEGF 121 have been reported to be secreted in a wide variety of transformed cell lines (Senger et al, 1986; Connolly et al, 1989; Myoken et al, 1991; Kondo et al, 1994) and $\mathrm{VEGF}_{165}$ is an abundant species detectable in several tumours (Ferrara et al, 1992). In contrast, $\mathrm{VEGF}_{189}$ and $\mathrm{VEGF}_{206}$ exist on the cell surface as structural profiles possessing hydrophobic residues (Houck et al, 1991). On the other hand, several therapeutic studies show that the inhibition of the biological activity and/or the production of VEGF suppresses tumour angiogenesis and growth in vivo (Kim et al, 1993; Kondo et al, 1993; Asano et al, 1995; Borgstrom et al, 1996; Cheng et al, 1996; Saleh et al, 1996; Im et al, 1999), suggesting that tumour-derived VEGF plays a crucial role for tumour neovascular- 
isation in vivo. Therefore, the suppression of VEGF expression in tumours would become a potent clinical strategy in cancer therapy for regulating tumour angiogenesis.

Hyperthermic treatment of malignant tumours is one cancer therapy by which the possible mechanism of the proliferation of tumour cells is relatively inhibited (Urano et al, 1983; Cellier et al, 1993). In addition, Toyota et al (1997) reported that a wholebody hyperthermia inhibits metastasis of breast cancer cells in rat in vivo. Moreover, it has been reported that not only progression but also metastasis of tumours are inhibited in most cases of cancer patients treated with a whole-body hyperthermia (Takeuchi et al, 1996, 1999). We recently reported that heat shock suppresses in vitro invasive activity of human fibrosarcoma HT-1080 cells by suppressing the production of membrane type 1-MMP (MT1MMP) and the activation of proMMP-2/progelatinase A (Sato et al, 1999; Sawaji et al, 2000). On the other hand, Fajardo et al (1988) reported that hyperthermia inhibits angiogenesis in vivo. Therefore, it is likely that hyperthermia is efficacious for preventing tumour metastasis and invasion, but it remains unclear whether hyperthermia could influence the expression of VEGF in tumour cells.

In the present study, we investigated the effect of heat shock on the production of VEGF in HT-1080 cells and the biological activities of conditioned medium from heat-shocked HT-1080 cells for endothelial-cell proliferation and proMMP-1/interstitial procollagenase production. Heat shock suppressed the constitutively expressed gene and the production of alternative splicing variants of VEGF in HT-1080 cells. Similar suppression of VEGF level was observed in vivo when patients with different cancers were treated with the whole-body hyperthermia. In addition, the augmentation of endothelial-cell proliferation and proMMP-1 production was reduced in the conditioned medium from heatshocked HT-1080 cells. Therefore, we suggest that hyperthermia suppresses angiogenesis by inhibiting the production of tumourderived VEGF in vivo and in vitro.

\section{MATERIALS AND METHODS}

\section{Cell culture and heat-shock treatment}

Human fibrosarcoma HT-1080 cells (Health Science Research Bank, Osaka, Japan) were cultured in MEM (Life Technologies, Inc., Grand Island, NY, USA) supplemented with 10\% FBS (Asahi Techno Glass Co., Tokyo, Japan) and MEM non-essential amino acids (Life Technologies). Human umbilical vein endothelial cells (HUVECs) (Takara Shuzo Co., Shiga, Japan) were cultured in EBM supplemented with $2 \% \mathrm{FBS}, 10 \mathrm{ng} \mathrm{ml}^{-1}$ human epidermal growth factor and $12 \mu \mathrm{g} \mathrm{ml}^{-1}$ bovine brain extract (Takara Shuzo). In the heat-shock experiments, confluent HT-1080 cells were treated with heat shock at $42^{\circ} \mathrm{C}$ for $4 \mathrm{~h}$ in MEM supplemented with $0.2 \%$ lactalbumin hydrolysate and then incubated for another $24 \mathrm{~h}$ at $37^{\circ} \mathrm{C}$ (Sato et al, 1999; Sawaji et al, 2000). The harvested culture medium was used for assay of endothelial-cell proliferation and Western blot analysis as described below.

\section{Semiquantification of VEGF mRNA by reverse transcriptase-polymerase chain reaction (RT - PCR)}

Cytoplasmic RNA in untreated and heat-shocked HT-1080 cells was isolated by ISOGEN (Nippon Gene Co., Toyama, Japan) according to the manufacturer's instructions. One microgram of the isolated RNA was subjected to the synthesis of first-strand cDNA by Moloney-murine leukaemia virus reverse transcriptase, RNase inhibitor (Roche Diagnostics, Tokyo, Japan) and oligo(dT) ${ }_{12-18}$ primer (Life Technologies) for $1 \mathrm{~h}$ at $37^{\circ} \mathrm{C}$. One-tenth of the cDNA generated from the RT reaction was used for PCR amplification for human VEGF and human glyceraldehyde-3-phosphate dehydrogenase (GAPDH). To detect the individual splicing variants for VEGF, a common forward primer and variant-specific reverse primers were designed (Table 1). The forward and reverse primers for human GAPDH were $5^{\prime}$ CCACCCATGGCAATTCCATGGCA- $3^{\prime}$ and $5^{\prime}$-TCTAGACGGCAGGTCAGGTCCACC-3', respectively. Polymerase chain reaction (PCR) was performed with $92^{\circ} \mathrm{C}$ for $40 \mathrm{~s}$, at $54^{\circ} \mathrm{C}$ for $40 \mathrm{~s}$ and $72^{\circ} \mathrm{C}$ for 1 min with 25-29 cycles for VEGFs and GAPDH. The amplified PCR products were analysed on $1 \%$ agarose gel and visualised by ethidium bromide staining. The PCR products were subcloned into pGEM-T vector (Promega, Madison, WI, USA), and then the cDNA sequence was confirmed with a Sequenase version 2.0 DNA sequencing kit (Amersham Biosciences, Tokyo, Japan) according to the manufacturer's instructions. The relative amounts of the amplified gene for VEGFs were quantified by densitometric scanning using the Image Analyzer LAS-1000 plus (Fuji Photo Film Co., Ltd., Tokyo, Japan) and then indicated after correction for that of GAPDH.

\section{Western blot analysis for VEGF and proMMP-1}

The production of VEGF in HT-1080 cells, and that of proMMP-1 in HUVECs were monitored by Western blot analysis with antibodies against human VEGF and human proMMP-1, respectively. Briefly, the harvested culture medium was subjected to SDS-PAGE with $12.5 \%$ and $10 \%$ acrylamide gel to detect VEGF and proMMP1 , respectively, and then proteins separated in the gel were electrotransferred onto a nitrocellulose membrane as described previously (Takahashi et al, 1991). The membrane was reacted with rabbit anti-(human VEGF) antibody (IBL, Gunma, Japan) or sheep anti-(human proMMP-1) antibody (kindly provided by Dr Hideaki Nagase), which was then complexed with horseradish peroxidaseconjugated goat anti-(rabbit IgG)IgG or goat anti-(sheep IgG)IgG (Sigma Chemical Co., St. Louis, MO, USA), respectively. Immunoreactive VEGF and proMMP-1 were visualised with ECLWestern blotting detection reagents (Amersham Biosciences) according to the manufacturer's instructions. The relative amounts of VEGF and proMMP-1 were quantified by densitometric scanning using the Image Analyzer LAS-1000 plus (Fuji Photo Film).

\section{Endothelial-cell proliferation assay}

HUVECs (500 cells well ${ }^{-1}$ ) were seeded into 96-multi well plates and cultured for $24 \mathrm{~h}$ at $37^{\circ} \mathrm{C}$ to achieve cell adhesion. The cells were washed twice with $\mathrm{Ca}^{2+}$ - and $\mathrm{Mg}^{2+}$-free phosphate buffered saline (PBS) and then incubated for the indicated periods with the HT-1080 cell-conditioned medium which was diluted $1: 1$ (vol: vol) with $0.5 \%$ FBS/EBM. The proliferation of HUVECs was monitored by alamer Blue assay (Wako Pure Chemical Co., Osaka, Japan) (Ahmed et al, 1994) according to the manufacturer's instructions. The fluorescence was measured by excitation at $540 \mathrm{~nm}$ and emission at $590 \mathrm{~nm}$.

\section{Neutralizing experiment with antibodies}

The HT-1080 cell-conditioned medium was incubated first with $50 \mu \mathrm{g} \mathrm{ml}^{-1}$ of polyclonal antibody against human VEGF, human TGF- $\alpha$, human tumour necrosis factor- $\alpha$ (TNF- $\alpha$ ) (R\&D Systems Inc., Minneapolis, MN, USA) or monoclonal antibody against human bFGF (Transduction Laboratories, Lexington, KY, USA) at $4^{\circ} \mathrm{C}$ for $24 \mathrm{~h}$ and then incubated with Protein A-Sepharose (Amersham Biosciences) for $1 \mathrm{~h}$ at room temperature. The Protein ASepharose-IgG complex was precipitated by centrifugation at $10000 \times g$ for $10 \mathrm{~min}$ and the resultant supernatant was sterilised and then used for the assay of endothelial-cell proliferation and proMMP-1 production as described above.

\section{Whole-body hyperthermia}

Whole-body hyperthermia was performed with a far-infrared radiation heat device, using the instruments RHD2002 and RHS7500 
Table I PCR primer sets for amplification of human VEGF splicing variants

\begin{tabular}{|c|c|c|c|c|c|}
\hline \multirow[b]{2}{*}{ Gene } & \multicolumn{2}{|r|}{ Forward } & \multicolumn{2}{|r|}{ Reverse } & \multirow[b]{2}{*}{ Product size } \\
\hline & Primer & Sequence (location) & Primers & Sequence (location) & \\
\hline $\begin{array}{l}V^{V G G} F_{121} \\
\operatorname{VEGF}_{165} \\
\operatorname{VEGF}_{189}\end{array}$ & $v-F$ & $\begin{array}{c}\text { 5'-CTTGGGTGCATTGGAGCCTTGCCT-3' } \\
(17-40 \mathrm{bp})\end{array}$ & $\begin{array}{l}v 121-R \\
v 165-R \\
v \mid 89-R\end{array}$ & $\begin{array}{l}\text { 5'-CCGCCTCGGCTTGTCACATTTTTC-3' (4I8-44I bp) } \\
\text { 5'-TGAGCAAGGCCCACAGGGATTTTC-3' (4I8-44I bp) } \\
\text { 5'-CCCACAGGGAACGCTCCAGGACTT-3' (48I-504 bp) }\end{array}$ & $\begin{array}{l}425 \mathrm{bp} \\
425 \mathrm{bp} \\
488 \mathrm{bp}\end{array}$ \\
\hline
\end{tabular}

(Enthermics Medical Systems Inc., Menomonee Falls, WI, USA) (Robins et al, 1985). Patients were anaesthetised and then subjected to the hyperthermia by maintaining a temperature of $42-43^{\circ} \mathrm{C}$ locally in the hyperthermic chamber and $41.5-42^{\circ} \mathrm{C}$ systemically (rectal temperature) for $1 \mathrm{~h}$ (Takeuchi et al, 1996). The hyperthermic therapy was performed once a week for 4 weeks. Two-seven days prior to the first treatment, and 2-3 weeks after the completion of the whole-body hyperthermia, blood was collected from the patients and then the serum level of VEGF was measured by VEGF immunoassay. This therapeutic treatment was performed only after approval of the protocol by the ethics committee of the hospital and after obtaining informed consent.

\section{Measurement of VEGF}

The levels of VEGF in sera from six cancer patients before and after whole-body hyperthermia were measured by human VEGF Immunoassay kit (R\&D Systems) according to the manufacturer's instructions. A VEGF antibody contained in this kit recognises both $\mathrm{VEGF}_{121}$ and $\mathrm{VEGF}_{165}$, and thus the immunoassay can be used to determine mass values for human $\mathrm{VEGF}_{121}$ and $\mathrm{VEGF}_{165}$.

\section{Statistical analysis}

Data were analysed by Student's $t$-test. $P<0.01$ was considered to be statistically significant.

\section{RESULTS}

\section{Gene expression of VEGF variants in HT-1080 cells}

The VEGF gene consists of the common exons $1-5$ and the individually specific exons for the variants: exon 8 for $\mathrm{VEGF}_{121}$, exons 7 and 8 for $\mathrm{VEGF}_{165}$, and exons 6,7 and 8 for $\mathrm{VEGF}_{189}$ (Figure 1). A common forward primer for VEGF (v-F) (17-40 bp, exon 1) was designed downstream from the start codon (Table 1 and Figure 1). Specific reverse primers for $\mathrm{VEGF}_{121}$ (v121-R), VEGF 165 (v165R) and $\mathrm{VEGF}_{189}$ (v189-R) were also designed across exons 5 and 8 (418-441 bp), exons 5 and $7(418-441 \mathrm{bp})$ and exons 6 and 7 (481-504 bp), respectively (Table 1 and Figure 1). We first characterised the expression of VEGF transcripts in HT-1080 cells by RTPCR analysis using these PCR primers. As shown in Figure 2, the

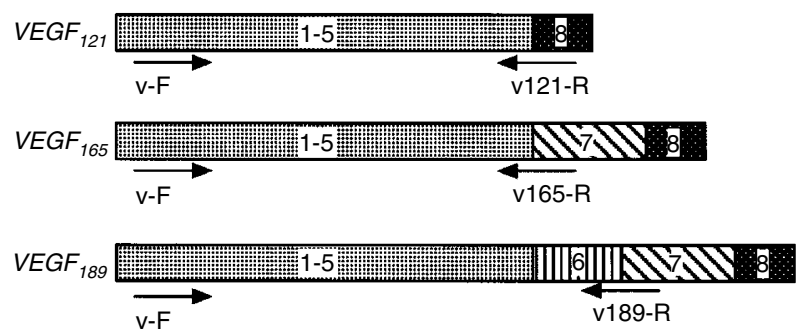

Figure I Structure of human VEGF mRNA. Exons are represented by box and numbered. Arrows indicate the specific primers for VEGF variants as shown in Table I. gene expression of $\operatorname{VEGF}_{121}$ (425 bp), $\operatorname{VEGF}_{165}$ (425 bp) and VEGF $_{189}$ (488 bp) was detected in HT-1080 cells and the amplification was cycle number-dependent. In addition, the gene level of $\mathrm{VEGF}_{189}$ was found to be less than that of $\mathrm{VEGF}_{121}$ and $\mathrm{VEGF}_{165}$ in HT-1080 cells. Furthermore, we confirmed that the DNA sequence of the amplified VEGF variants was completely identical to that in the previous paper by Leung et al (1989) (data not shown). However, we did not detect a $\mathrm{VEGF}_{206}$ transcript in HT1080 cells by RT - PCR using the common forward primer and a specific reverse one that was designed with a terminal codon in exon 8 (data not shown).

\section{Heat shock suppresses gene expression and production of VEGF in HT-1080 cells}

We examined the influence of heat shock on the gene expression of VEGF variants in HT-1080 cells. When the cells were pretreated with heat shock at $42^{\circ} \mathrm{C}$ for $4 \mathrm{~h}$ and then incubated for another $24 \mathrm{~h}$ at $37^{\circ} \mathrm{C}, \mathrm{VEGF}_{121}, \mathrm{VEGF}_{165}$ and $\mathrm{VEGF}_{189}$ transcripts were decreased to 34,45 and $41 \%$, respectively, of the values for the untreated cells (Figure 3). Western blot analysis showed that HT-1080 cells produced abundant $\mathrm{VEGF}_{165}$ with the same mobility of recombinant human $\mathrm{VEGF}_{165}$ (Figure 4, lane 1). The production of VEGF $_{165}$ in heat-shocked HT-1080 cells was suppressed to $53 \%$ of the values for untreated cells (Figure 4, lane 2). In addition, VEGF $_{121}$ was detected in HT-1080 cells, but in a much smaller amount than $\mathrm{VEGF}_{165}$, and its production was similarly suppressed by heat shock (Figure 4, lanes 1 and 2). Therefore, these results suggest that heat shock suppresses the production of $\mathrm{VEGF}_{165}$ and $\mathrm{VEGF}_{121}$ through the depression of their mRNA expression in HT-1080 cells.

\section{Effect of conditioned medium from heat-shocked HT-1080 cells on proliferation of HUVECs}

VEGF possesses the mitogenic activity to cause proliferation of endothelial cells in angiogenesis (Leung et al, 1989; Connolly et al, 1989; Ferrara et al, 1992). We next examined the endothelial-cell proliferative activity of conditioned medium from untreated and heat-shocked HT-1080 cells. When the conditioned medium from HT-1080 cells was added to HUVECs, the endothelial-cell proliferation was increased in a time-dependent manner and doubled for 3 days (Figure 5, filled triangles). However, the conditioned medium from heat-shocked HT-1080 cells no longer indicated proliferative activity toward HUVECs (Figure 5, filled squares). On the other hand, as shown in Figure 6, the enhancement of endothelial-cell proliferation by the conditioned medium from HT-1080 cells (lane 2) was neutralised with an antibody against VEGF (lane 3), but not by an antibody to bFGF (lane 4), which is known as another angiogenic factor in vivo and in vitro (Abraham et al, 1986; Gospodarowicz et al, 1987). In addition, we confirmed that neither TGF- $\alpha$ nor TNF- $\alpha$ antibody interfered with the proliferative activity on HUVECs (data not shown). These results indicate that the enhancement of endothelial-cell proliferation by conditioned medium from HT-1080 cells was mediated specifically by VEGF, and suggest that heat shock is adequate for inhibiting the endothelial-cell proliferation by suppressing tumour-derived VEGF production. 


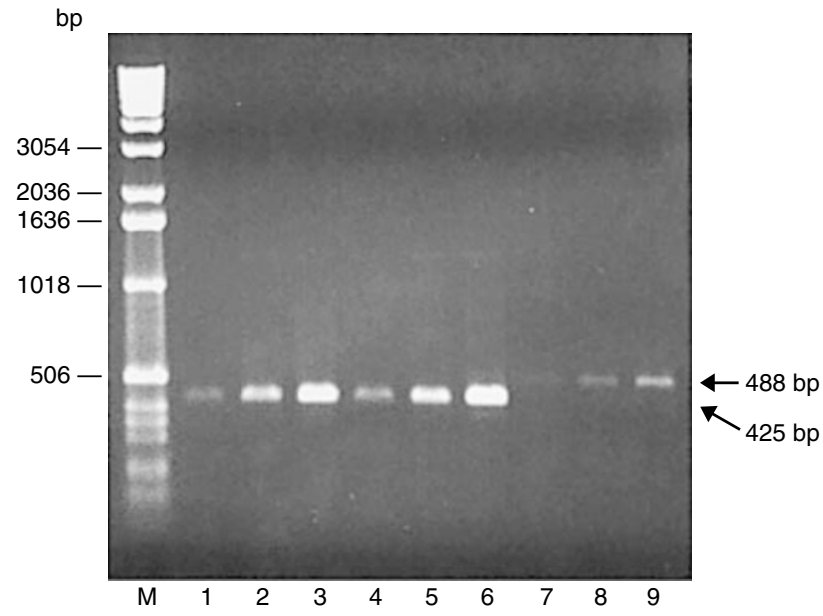

Figure 2 Characterisation of gene expression of VEGF splicing variants in human fibrosarcoma HT- 1080 cells. Isolated RNA (I $\mu \mathrm{g})$ was subjected to RT-PCR analysis with 25 (lanes I, 4 and 7), 27 (lanes 2, 5 and 8) and 29 cycles (lanes 3, 6 and 9) using specific primers for respective VEGF splicing variants; VEGF $121, V E_{165}$ and $V E_{189}$ as indicated in Figure I and Table I. Two independent experiments were reproducible and typical data were shown. Lanes I -3, VEGF 12 I; lanes 4-6, VEGF 165 and lanes 7-9, VEGF 189.

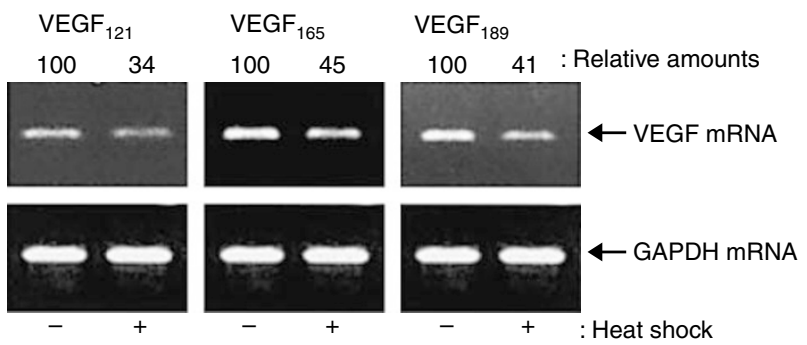

Figure 3 Heat shock suppresses gene expression of VEGF variants in HT-I080 cells. Confluent HT- 1080 cells were treated with or without heat shock at $42^{\circ} \mathrm{C}$ for $4 \mathrm{~h}$ and then incubated for another $24 \mathrm{~h}$. Isolated RNA was subjected to RT-PCR analysis with 27 cycles for VEGF 121 and VEGF $_{165}$ and with 29 cycles for VEGF $_{189}$ as described in Figure 2. The relative amounts of VEGF mRNA were quantified by densitometric scanning followed by normalising against that of GAPDH mRNA and expressed taking the untreated HT-1080 cells as 100. Three independent experiments were reproducible and typical data were shown.

\section{Effect of conditioned medium from heat-shocked HT-1080 cells on production of endothelial proMMP-1}

The augmentation of proteolytic activity is crucial for extracellular matrix (ECM) remodelling in order to provide a permissive environment in which activated endothelial cells can proliferate and form new vessels (Moses, 1997; Liotta et al, 1991). In addition, endothelial MMPs such as MMP-1 and MT1-MMP have been shown to participate in ECM remodelling in the perivascular environment (Fisher et al, 1994; Hiraoka et al, 1998). We therefore investigated the effect of conditioned medium from HT-1080 cells on the production of proMMP-1 in HUVECs. Western blot analysis showed that the production of proMMP-1 in HUVEC was augmented by the conditioned medium from HT-1080 cells (6.2fold) as well as by recombinant human $\mathrm{VEGF}_{165}$ (4.2-fold) (Figure $7 \mathrm{~A}$, lanes 2 and 4, respectively). In addition, the augmentation of proMMP-1 production was inhibited by adding a neutralising antibody against VEGF (Figure 7A, lanes 3 and 5). Furthermore, the augmentation of proMMP-1 production was poor in HUVECs treated with the conditioned medium from heat-shocked HT1080 cells rather than that from untreated HT-1080 cells (Figure

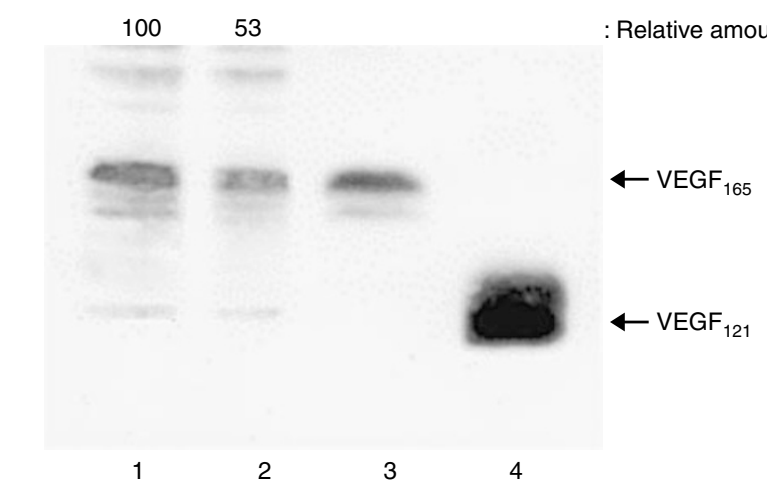

Figure 4 Heat shock suppresses production of VEGF in HT-1080 cells. Confluent HT-I 080 cells were treated with or without heat shock as described in Figure 3. The harvested culture medium was subjected to Western blot analysis for VEGF as described in Materials and Methods. The relative amounts of $V E G_{165}$ were quantified by densitometric scanning and expressed taking the untreated HT-I080 cells as I00. Three independent experiments were reproducible and typical data were shown. Lane I, untreated HT-I080 cells; lane 2, heat-shocked HT-I080 cells; lane 3, recombinant human $V \mathrm{VGF}_{165}(10 \mathrm{ng})$ and lane 4, recombinant human VEGF $_{12 \mid}(20 \mathrm{ng})$.

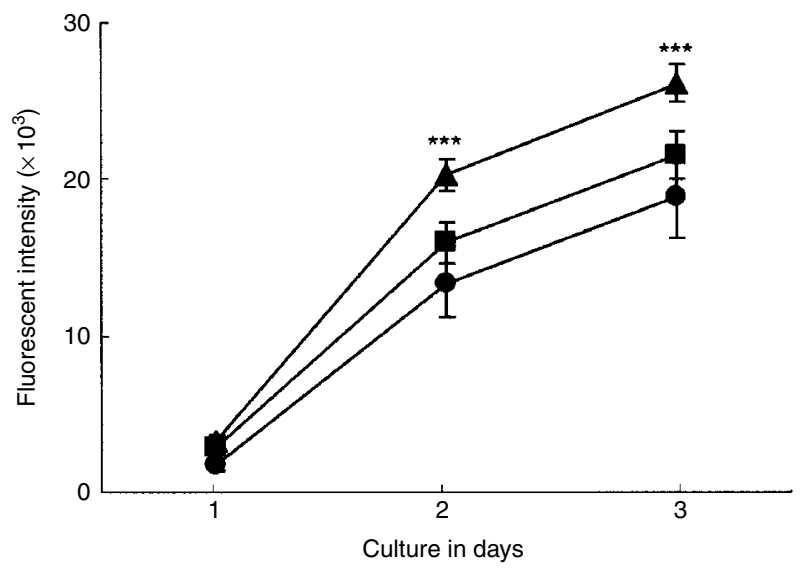

Figure 5 Proliferation of HUVECs by HT-I 080 cell-derived conditioned medium. HUVECs (500 cells well ${ }^{-1}$ ) were treated with control medium (filled circles), with the HT-I080 cell-conditioned medium (filled triangles) or with the heat-shocked HT-I080 cell-conditioned medium (filled squares). The proliferation of HUVECs was monitored by alamer Blue assay as described in Materials and Methods. The data are the mean \pm s.d. of values from six wells at each point. *** Significantly different from HUVECs treated with control medium $(P<0.00 \mathrm{I})$. Two independent experiments were reproducible and typical data were shown.

$7 \mathrm{~B}$, lanes 2 and 3). These results suggest that heat shock is efficacious in the prevention of MMP-dependent ECM remodelling in the process of angiogenesis by suppressing the production of tumour-derived VEGF.

\section{Whole-body hyperthermia diminishes the serum level of VEGF in cancer patients in vivo}

To clarify whether hyperthermia inhibits the production of VEGF in vivo, we investigated the serum level of VEGF in various cancer patients before and after whole-body hyperthermia at $42^{\circ} \mathrm{C}$ (Takeuchi et al, 1996, 1999). The patient characteristics are listed in Table 2. Six patients had various forms of advanced cancer, and the histology and tumour-node-metastasis (TNM) in the individual patients were characterised at the initial diagnosis. In addition, five 


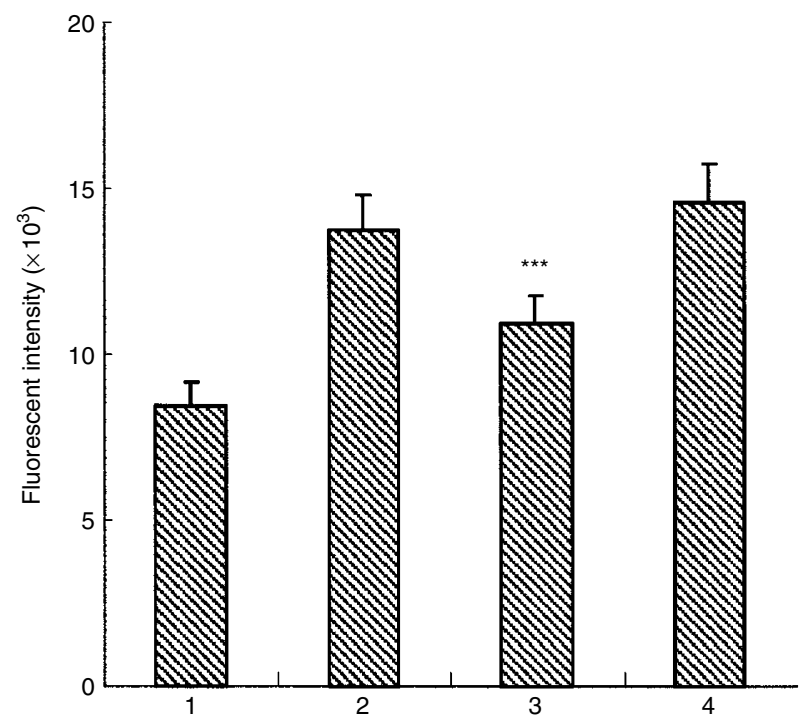

Figure 6 Characterisation of HT-I080 cell-derived factor for endothelial-cell proliferation. Conditioned medium from HT-I080 cells was pretreated with an antibody against VEGF $\left(50 \mu \mathrm{g} \mathrm{ml}^{-1}\right)$ or bFGF $\left(50 \mu \mathrm{g} \mathrm{ml}^{-1}\right)$ and then HUVECs (500 cells well ${ }^{-1}$ ) were treated with or without the conditioned medium. After 2 days treatment, the proliferation of HUVECs was monitored by alamer Blue assay as described in Figure 5. The data are the mean \pm s.d. of values from six wells. Two independent experiments were reproducible and typical data were shown Lane I, HUVECs cultured in control medium; lane 2, HUVECs treated with the HT-I080 cell-conditioned medium; lane 3, HUVECs treated with the HT-I080 cell-conditioned medium pretreated with VEGF antibody and lane 4, HUVECs treated with the HT-I080 cell-conditioned medium pretreated with bFGF antibody. ***Significantly different from HUVECs treated with the HT-I080 cell-conditioned medium $(P<0.00 \mathrm{I})$.

of these patients had received previous chemotherapy and/or radiotherapy. When sera from these patients were collected 2-7 days prior to the first whole-body hyperthermia, the serum level of VEGF was higher than $100 \mathrm{pg} \mathrm{ml}^{-1}$ in all patients and its average $\left( \pm\right.$ s.d) was $177.0( \pm 77.5) \mathrm{pg} \mathrm{ml}^{-1}$ (Table 2$)$. Two-three weeks after completion of the hyperthermic therapy, the level of VEGF decreased to $49.9( \pm 36.5) \mathrm{pg} \mathrm{ml}^{-1}$, which was almost the same as the normal VEGF level (Hyodo et al, 1998). Therefore, it is suggested that whole-body hyperthermia efficiently diminishes the level of VEGF in advanced cancer patients.

\section{DISCUSSION}

VEGF has been characterised as existing in four isoforms; $\mathrm{VEGF}_{121}$, $\mathrm{VEGF}_{165}, \mathrm{VEGF}_{189}$ and $\mathrm{VEGF}_{206}$ (Ferrara et al, 1992). To individually and specifically amplify these variants by semi-quantitative RT-PCR, we designed unique PCR primers and demonstrated that HT-1080 cells expressed predominantly VEGF $_{121}$ and VEGF $_{165}$ mRNA as well as a smaller amount of the $V_{E G F}{ }_{189}$ transcript, and did not express $\mathrm{VEGF}_{206}$. In addition, Western blot analysis showed that the immunoreactive VEGF was mostly VEGF 165 and a smaller amount of $\mathrm{VEGF}_{121}$, while the mRNA level of both isoforms was the same in HT-1080 cells. No immunologically detected VEGF variants could be found in the cell-membrane fraction of HT-1080 cells (data not shown), although VEGF 189 and VEGF $_{206}$ exist as cell-associated forms (Houck et al, 1991). On the other hand, tumour cells have been shown to produce other angiogenic factors such as bFGF (Abraham et al, 1986; Gospodarowicz et al, 1987), TGF- $\alpha$ (Smith et al, 1987) and PDGF (Holmgren et al, 1991; Risau et al, 1992). We demonstrated that the proliferation of HUVECs by conditioned medium derived from
A

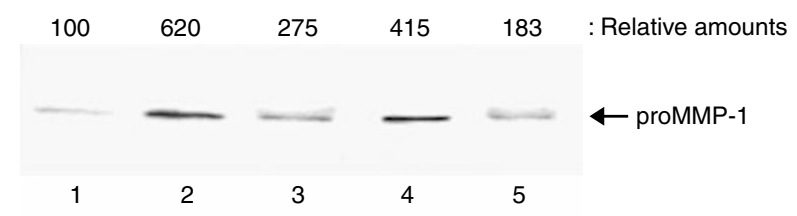

B

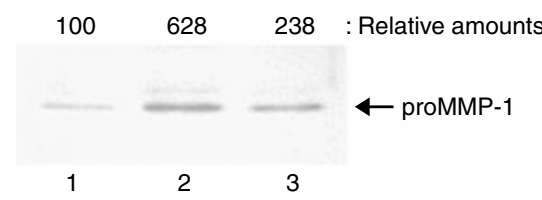

Figure 7 HT-I080 cell-derived VEGF stimulates HUVECs to produce proMMP-I. (A) Conditioned medium from HT-I 080 cells and the culture medium supplemented with human recombinant VEGF $165\left(20 \mathrm{ng} \mathrm{ml}^{-1}\right)$ were pretreated with or without an antibody against VEGF $\left(50 \mu \mathrm{g} \mathrm{ml}^{-1}\right)$ and then HUVECs were treated with these conditioned media for $24 \mathrm{~h}$. The harvested culture medium was subjected to Western blot analysis for proMMP-I as described in Materials and Methods. Lane I, untreated HUVECs; lane 2, HUVECs treated with the HT-I080 cell-conditioned medium; lane 3, HUVECs treated with the HT- 1080 cell-conditioned medium pretreated with VEGF antibody; lane 4, HUVECs treated with recombinant human VEGF 165 and lane 5, HUVECs treated with recombinant human VEGF 165 pretreated with VEGF antibody. (B) Confluent HUVECs were treated with or without conditioned medium from untreated or heat-shocked HT- I080 cells. Three independent experiments were reproducible and typical data were shown. Lane I, untreated HUVECs; lane 2, HUVECs treated with the HT-I080 cell-conditioned medium and lane 3, HUVECs treated with the heat-shocked HT- 1080 cell-conditioned medium. The relative amounts of proMMP-I production were quantified by densitometric scanning and expressed taking the untreated HUVECs as 100.

HT-1080 cells was effectively prevented by adding VEGF antibody, but not by adding antibodies to bFGF, TGF- $\alpha$ and TNF- $\alpha$ (data not shown). Therefore, it is suggested that the angiogenic factor derived from HT-1080 cells is primarily VEGF $_{165}$.

Exposing malignant cells to hyperthermia is a therapeutic strategy that prevents tumour progression by inhibiting the proliferation of tumour cells (Urano et al, 1983). Fajardo et al (1988) also reported that hyperthermia inhibits angiogenesis by interference with cell replication and/or inhibition of the migration of vascular endothelial cells. However, the effect of hyperthermia on the production of VEGF is not specified. In the present study, we demonstrated for the first time that heat shock suppresses the gene expression and the production of VEGF $_{165}$ in HT-1080 cells. Moreover, the heat shock-mediated suppressions of both $\mathrm{VEGF}_{165}$ production and its gene expression were similarly observed in human squamous carcinoma A431 cells (data not shown). Thus, this novel evidence that heat shock directly down-regulates the expression of VEGFs in HT-1080 cells is likely to be ubiquitously observed in tumour cells.

Endothelial cells are basically quiescent, but when activated by VEGF, they turn into the angiogenic phenotype and then proliferate and migrate to form new vessels in vivo and in vitro (Weidner et al, 1991; Ferrara et al, 1992). In addition, VEGF-mediated neovascularisation is closely associated with tumour growth in vivo (Kim et al, 1993; Asano et al, 1995; Cheng et al, 1996; Im et al, 1999). In fact, Kim et al (1993) reported that the intraperitoneal injection of a specific monoclonal antibody for human $\mathrm{VEGF}_{165}$ inhibits the growth of rhabdomyosarcoma, glioblastoma multiforme and leiomyosarcoma cell lines in nude mice. Im et al (1999) also reported that an antisense cDNA molecule of VEGF induces anti-tumorigenic effects in vivo on human glioma tumours 
Table 2 The patient characteristics and the serum level of VEGF before and after whole-body hyperthermia

\begin{tabular}{|c|c|c|c|c|c|c|c|c|}
\hline \multicolumn{2}{|c|}{ Patients } & \multirow[b]{2}{*}{ Primary cancer } & \multirow[b]{2}{*}{ Histology ${ }^{a}$} & \multirow[b]{2}{*}{ TNM $^{\mathrm{b}}$} & \multirow[b]{2}{*}{ Metastasis $^{c}$} & \multirow[b]{2}{*}{$\mathrm{CH} / \mathbf{R D}^{\mathrm{d}}$} & \multicolumn{2}{|c|}{ VEGF $\left(p g \mathrm{ml}^{-1}\right)$} \\
\hline No. & Sex & & & & & & Before WBH & After WBH \\
\hline । & Female & Thyroid cancer & PC & T2NIMI & Bone & $\mathrm{RD}$ & 194.1 & 83.3 \\
\hline 3 & Male & Gastric cancer & $A D, W$ & T4NIMO & ND & $\mathrm{CH}$ & 231.7 & 89.8 \\
\hline 4 & Male & Rectal cancer & $A D$ & T3N2MI & Brain, Lung & $\mathrm{CH}$ & 107.2 & 7.1 \\
\hline 5 & Female & Ureteral cancer & $\mathrm{TC}$ & T2N2MO & Bladder & $\mathrm{CH} / \mathrm{RD}$ & 119.0 & 27.7 \\
\hline 6 & Male & Pancreatic cancer & ICCA & T4NIMI & Liver & $\mathrm{CH}$ & 113.0 & 74.0 \\
\hline
\end{tabular}

Sera from six patients $(\mathrm{I}-6)$ with various forms of cancer were individually collected before and after whole-body hyperthermia $(\mathrm{WBH})$ and then subjected to $\mathrm{VEGF}$ immu-

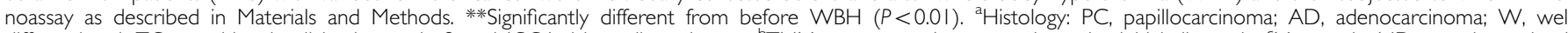
differentiated, TC, transitional cell in the grade 3 and ICCA, islet cell carcinoma. ${ }^{\mathrm{b}} \mathrm{TNM}$, tumour-node-metastasis at the initial diagnosis. ${ }^{\mathrm{C}}$ Metastasis: ND, not determined. ${ }^{\mathrm{d}} \mathrm{CH} / \mathrm{RD}$ : the previous history of chemotherapy $(\mathrm{CH})$ and/or radiotherapy $(\mathrm{RD})$.

established in nude mice. Therefore, it is likely that VEGF is a clinical target molecule for cancer therapy. Thus, our finding that heat shock inhibited VEGF expression in tumour cells strongly suggests that hyperthermia might be one therapeutic strategy for preventing angiogenesis together with known therapeutic properties such as anti-tumorigenic activity in vivo.

Recently, Kanamori et al (1999) reported that hyperthermia at $44^{\circ} \mathrm{C}$ induces the expression of VEGF in SCC VII tumours in $\mathrm{C} 3 \mathrm{H} / \mathrm{He}$ mice, by the mechanism that heat-mediated vascular damage may attribute to hypoxia and thereafter tumour necrosis. This phenomenon is different from our finding, that heat shock suppresses VEGF expression in tumour cells. In our experiments, heat shock at $42^{\circ} \mathrm{C}$ for $4 \mathrm{~h}$ does not influence cellular functions such as biosynthesis of total proteins and tumour cell growth in vitro (Sato et al, 1999; Sawaji et al, 2000). Thus, the discrepancy may be due to the difference of experimental conditions such as temperature and heat-exposing period. Furthermore, we demonstrated that the level of VEGF in serum was diminished in all cancer patients treated with whole-body hyperthermia. Therefore, it is very likely that the in vitro findings in the present study reflect on the in vivo effect of whole-body hyperthermia, and that the suppression of tumour progression and metastasis by whole-body hyperthermia may partly contribute to the prevention of angiogenesis by inhibiting VEGF production in vivo.

Extracellular matrix remodelling is required for endothelial-cell proliferation and migration in the process of angiogenesis, and is closely dependent on endothelial cell-derived proteinases such as MMPs (Liotta et al, 1991; Moses, 1997). Endothelial MMP-1 has been shown to participate in angiogenesis in vitro (Unemori et al, 1992; Fisher et al, 1994). A recent study by Hiraoka et al (1998) also reported that MT1-MMP in endothelial cells is involved in neovessel formation in mice deficient in both plasminogen activator and plasminogen. In this communication, we indicated that HT-1080 cells produced a large amount of VEGF by which the production of proMMP-1 in HUVECs was augmented, and also that heat shock effectively interfered with the production of VEGF. Furthermore, we recently reported that heat shock suppresses in vitro tumour invasive activity by suppressing the production of MT1-MMP and thereafter inhibiting the activation of proMMP-2 in tumour cells (Sato et al, 1999; Sawaji et al, 2000). Therefore, it is suggested that hyperthermia elicits not only an anti-angiogenic effect by inhibiting tumour-derived VEGF production but also an anti-metastatic action by suppressing the production and activation of proMMPs.

In conclusion, we demonstrated that heat shock suppresses the gene expression of three VEGF splicing variants, $V_{E G F}{ }_{121}, V E_{165}$ and $\mathrm{VEGF}_{189}$, and decreases the predominant product of $\mathrm{VEGF}_{165}$ in HT-1080 cells. In addition, the heat shock-mediated suppression of VEGF production results in the inhibition of tumour cellinduced proliferation and MMP production in endothelial cells. Furthermore, whole-body hyperthermia diminished the augmented level of VEGF in serum from patients with advanced cancers in vivo. Therefore, these results strongly suggest that this suppression by hyperthermia of tumour cell-derived VEGF production may explain, in part, the reason why hyperthermic therapy effectively prevents tumor growth and metastasis in vivo.

\section{ACKNOWLEDGEMENTS}

This work was supported in part by the Japan Private School Promotion Foundation and by a Grant-in-Aid for Scientific Research from the Ministry of Education, Science and Culture of Japan (No. 12672122). We thank Dr Hideaki Nagase (The Kennedy Institute of Rheumatology, Imperial College, London, UK) for his generous gift of sheep anti-(human proMMP-1)antibody.

\section{REFERENCES}

Abraham JA, Mergia A, Whang JL, Tumolo A, Friedman J, Hjerrild KA, Gospodarowicz D, Fiddes JC (1986) Nucleotide sequence of a bovine clone encoding the angiogenic protein, basic fibroblast growth factor. Science 233: $545-548$

Ahmed SA, Gogal Jr RM, Walsh JE (1994) A new rapid and simple nonradioactive assay to monitor and determine the proliferation of lymphocytes: An alternative to $\left[{ }^{3} \mathrm{H}\right]$ thymidine incorporation assay. J Immunol Methods 170: $211-224$

Asano M, Yukita A, Matsumoto T, Kondo S, Suzuki H (1995) Inhibition of tumor growth and metastasis by an immunoneutralizing monoclonal antibody to human vascular endothelial growth factor/vascular permeability factor $_{121}$. Cancer Res 55: 5296-5301

Borgstrom P, Hillan KJ, Sriramarao P, Ferrara N (1996) Complete inhibition of angiogenesis and growth of microtumors by anti-vascular endothelial growth factor neutralizing antibody: Novel concepts of angiostatic therapy from intravital videomicroscopy. Cancer Res 56: 4032-4039

Cellier MF, Taimi M, Chateau MT, Cannat A, Marti J (1993) Thermal stress as an inducer of differentiation of U937 cells. Leukemia Res 17: $649-656$

Cheng S-Y, Huang H-JS, Nagane M, Ji X-D, Wang D, Shih CC-Y, Arap W, Huang C-M, Cavenee WK (1996) Suppression of glioblastoma angiogenicity and tumorigenicity by inhibition of endogenous expression of vascular endothelial growth factor. Proc Natl Acad Sci USA 93: 8502-8507 
Connolly DT, Olander JV, Heuvelman D, Nelson R, Monsell R, Siegel N, Haymore BL, Leimgruber R, Feder J (1989) Human vascular permeability factor. Isolation from U937 cells. J Biol Chem 264: 20017-20024

Fajardo LF, Prionas SD, Kowalski J, Kwan HH (1988) Hyperthermia inhibits angiogenesis. Radiat Res 114: 297 -306

Ferrara N, Henzel WJ (1989) Pituitary follicular cells secrete a novel heparinbinding growth factor specific for vascular endothelial cells. Biochem Biophys Res Commun 161: 851-858

Ferrara N, Houck K, Jakeman L, Leung DW (1992) Molecular and biological properties of the vascular endothelial growth factor family of proteins. Endocr Rev 13: $18-32$

Fisher C, Gilbertson-Beadling S, Powers EA, Petzold G, Poorman R, Mitchell MA (1994) Interstitial collagenase is required for angiogenesis in vitro. Dev Biol 162: 499-510

Folkman J (1992) The role of angiogenesis in tumor growth. Cancer Biol 3: $65-71$

Gospodarowicz D, Ferrara N, Schweigerer L, Neufeld G (1987) Structural characterization and biological functions of fibroblast growth factor. Endocr Rev 8: $95-114$

Hiraoka N, Allen E, Apel IJ, Gyetko MR, Weiss SJ (1998) Matrix metalloproteinases regulate neovascularization by acting as pericellular fibrinolysins. Cell 95: $365-377$

Holmgren L, Glaser A, Pfeifer-Ohlsson S, Ohlsson R (1991) Angiogenesis during human extraembryonic development involves the spatiotemporal control of PDGF ligand and receptor gene expression. Development 113: $749-754$

Houck KA, Ferrara N, Winer J, Cachianes G, Li B, Leung DW (1991) The vascular endothelial growth factor family: Identification of a fourth molecular species and characterization of alternative splicing of RNA. Mol Endocrinol 5: 1806-1814

Hyodo I, Doi T, Endo H, Hosokawa Y, Nishikawa Y, Tanimizu M, Jinno K, Kotani Y (1998) Clinical significance of plasma vascular endothelial growth factor in gastrointestinal cancer. Eur J Cancer 34: 2041 - 2045

Im S-A, Gomez-Manzano C, Fueyo J, Liu T-J, Ke LD, Kim J-S, Lee H-Y, Steck PA, Kyritsis AP, Yung WKA (1999) Antiangiogenesis treatment for gliomas: transfer of antisense-vascular endothelial growth factor inhibits tumor growth in vivo. Cancer Res 59: 895-900

Kanamori S, Nishimura Y, Okuno Y, Horii N, Saga T, Hiraoka M (1999) Induction of vascular endothelial growth factor (VEGF) by hyperthermia and/or an angiogenesis inhibitor. Int J Hyperthermia 15: 267-278

Kim KJ, Li B, Winer J, Armanini M, Gillett N, Phillips HS, Ferrara N (1993) Inhibition of vascular endothelial growth factor-induced angiogenesis suppresses tumour growth in vivo. Nature 362: 841-844

Kondo S, Asano M, Suzuki H (1993) Significance of vascular endothelial growth factor/vascular permeability factor for solid tumor growth, and its inhibition by the antibody. Biochem Biophys Res Commun 194: $1234-1241$

Kondo S, Asano M, Matsuo K, Ohmori I, Suzuki H (1994) Vascular endothelial growth factor/vascular permeability factor is detectable in the sera of tumor-bearing mice and cancer patients. Biochim Biophys Acta 1221: $211-214$

Kondo Y, Arii S, Mori A, Furutani M, Chiba T, Imamura M (2000) Enhancement of angiogenesis, tumor growth, and metastasis by transfection of vascular endothelial growth factor into LoVo human colon cancer cell line. Clin Cancer Res 6: 622-630

Leung DW, Cachianes G, Kuang W-J, Goeddel DV, Ferrara N (1989) Vascular endothelial growth factor is a secreted angiogenic mitogen. Science 246: $1306-1309$

Liotta LA, Steeg PS, Stetler-Stevenson WG (1991) Cancer metastasis and angiogenesis: An imbalance of positive and negative regulation. Cell 64: $327-336$

Moses MA (1997) The regulation of neovascularization of matrix metalloproteinases and their inhibitors. Stem Cells 15: $180-189$
Myoken Y, Kayada Y, Okamoto T, Kan M, Sato GH, Sato JD (1991) Vascular endothelial cell growth factor (VEGF) produced by A-431 human epidermoid carcinoma cells and identification of VEGF membrane binding sites. Proc Natl Acad Sci USA 88: 5819-5823

Risau W, Drexler H, Mironov V, Smits A, Siegbahn A, Funa K, Heldin CH (1992) Platelet-derived growth factor is angiogenic in vivo. Growth Factors 7: $261-266$

Robins HI, Dennis WH, Neville AJ, Shecterle LM, Martin PA, Grossman J, Davis TE, Neville SR, Gillis WK, Rusy BF (1985) A nontoxic system for $41.8^{\circ} \mathrm{C}$ whole-body hyperthermia: Results of a Phase I study using a radiant heat device. Cancer Res 45: 3937-3944

Saleh M, Stacker SA, Wilks AF (1996) Inhibition of growth of C6 glioma cells in vivo by expression of antisense vascular endothelial growth factor sequence. Cancer Res 56: 393-401

Sato T, Sawaji Y, Matsui N, Sato H, Seiki M, Mori Y, Ito A (1999) Heat shock suppresses membrane type 1-matrix metalloproteinase production and progelatinase A activation in human fibrosarcoma HT-1080 cells and thereby inhibits cellular invasion. Biochem Biophys Res Commun 265: $189-193$

Sawaji Y, Sato T, Seiki M, Ito A (2000) Heat shock-mediated transient increase in intracellular $3^{\prime}, 5^{\prime}$-cyclic AMP results in tumor specific suppression of membrane type 1-matrix metalloproteinase production and progelatinase A activation. Clin Exp Metastasis 18: 131-138

Schreiber AB, Winkler ME, Derynck R (1986) Transforming growth factor- $\alpha$ : A more potent angiogenic mediator than epidermal growth factor. Science 232: $1250-1253$

Senger DR, Perruzzi CA, Feder J, Dvorak HF (1986) A highly conserved vascular permeability factor secreted by a variety of human and rodent tumor cell lines. Cancer Res 46: 5629-5632

Smith JJ, Derynck R, Korc M (1987) Production of transforming growth factor $\alpha$ in human pancreatic cancer cells: Evidence for a superagonist autocrine cycle. Proc Natl Acad Sci USA 84: 7567-7570

Takahashi S, Ito A, Nagino M, Mori Y, Xie B, Nagase H (1991) Cyclic adenosine $3^{\prime}, 5^{\prime}$-monophosphate suppresses interleukin 1-induced synthesis of matrix metalloproteinases but not of tissue inhibitor of metalloproteinases in human uterine cervical fibroblasts. J Biol Chem 266: 19894-19899

Takeuchi A, Shimizu M, Takeuchi T, Iijima N, Kobayashi J, Kobayashi Y, Ozaki M, Itabashi A, Yokoyama M (1999) Whole body mild hyperthermia by near-infrared rays. Jpn J Hyperthermic Oncol 15: 187-192

Takeuchi T, Takeuchi A, Chikuma S, Kobayashi Y, Kashiwagi S, Hasumura M, Yokoyama M (1996) Evaluation of therapy efficacy according to the far-infrared whole-body hyperthermia heat divice. Jpn J Hyperthermic Oncol 12: $156-163$

Tischer E, Mitchell R, Hartman T, Silva M, Gospodarowicz D, Fiddes JC, Abraham JA (1991) The human gene for vascular endothelial growth factor. Multiple protein forms are encoded through alternative exon splicing. J Biol Chem 266: $11947-11954$

Toyota N, Strebel FR, Stephens LC, Matsuda H, Bull JM (1997) Long-duration, mild whole body hyperthermia with cisplatin: Tumour response and kinetics of apoptosis and necrosis in a metastatic rat mammary adenocarcinoma. Int J Hyperthermia 13: 497-506

Unemori EN, Ferrara N, Bauer EA, Amento EP (1992) Vascular endothelial growth factor induces interstitial collagenase expression in human endothelial cells. J Cell Physiol 153: 557-562

Urano M, Rice L, Epstein R, Suit HD, Chu AM (1983) Effect of whole-body hyperthermia on cell survival, metastasis frequency, and host immunity in moderately and weakly immunogenic murine tumors. Cancer Res 43: $1039-1043$

Weidner N, Semple JP, Welch WR, Folkman J (1991) Tumor angiogenesis and metastasis-correlation in invasive breast carcinoma. $N$ Engl J Med 324: $1-8$ 